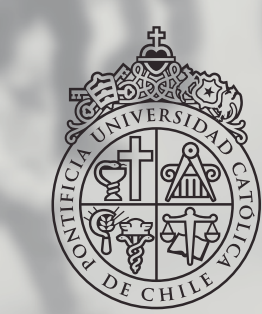

PONTIFICIA

UNIVERSIDAD

CATÓLICA

DE CHILE
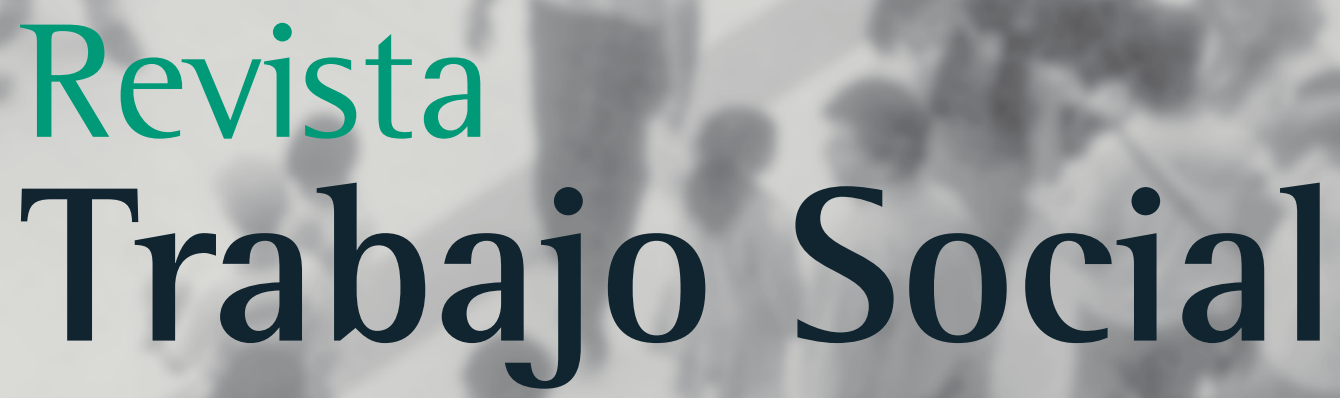

Intervención

socioambiental:

intersecciones del

Trabajo Social y la

institucionalidad

ambiental

Dr. Nelson Arellano-Escudero.

\section{Tensiones en la} Intervención Social:

(des)encuentros en la relación

Estado-ONG. Estudio de caso

sobre ONG que opera la política

social de infancia

Mauricio Sánchez Aliaga,

Rosa Villarroel Valdés.
Calidad de la participación infantil en la Política Local de Infancia Chilena

Daniela Díaz Bórquez,

Natalia Bozo Carrillo,

Nicolás Contreras SHats.

\section{Identidades Subyugadas}

entre Actores del Proceso

Penitenciario de Valparaíso

Paula Mercado Amin,

Fernanda Zavala Ossandón.

\section{Involucramiento} laboral

y disposición al cambio organizacional en el sector

de salud primaria

Carla Flores Figueroa,

LoRena MuÑoz MadRID,

Julia Jaramillo de Palacio. 



\title{
Tensiones en la Intervención Social: (des)encuentros en la relación Estado-ONG. Estudio de caso sobre ONG que opera la política social de infancia
}

\author{
Tensions in Social Intervention: (des)encounters in \\ the State-NGO relations. Case study on the NGO that \\ operates the social child policy.
}

Mauricio Sánchez Aliaga.

Escuela de Trabajo Social de la Universidad Andrés Bello, Magister Interdisciplinario en Intervención Social, Trabajador Social y Licenciado en Trabajo Social. Dirección Postal: Quillota 980, Viña del Mar.Correo electrónico: mauricio.sanchez@unab.cl.

Rosa Villarroel Valdés.

Escuela de Trabajo Social de la Universidad Andrés Bello. Magíster en Ciencias Sociales, mención Políticas Sociales, Asistente Social y Licenciada en Servicio Social. Dirección Postal: Quillota 980, Viña del Mar.Correo electrónico: rvillarroel@unab.cl.

\begin{abstract}
Resumen
Al analizar los procesos de intervención social desarrollados por Organizaciones No Gubernamentales (ONG) vinculadas a la ejecución de la política social de infancia, emergen una serie de tensiones, articulaciones y cuestionamientos en torno a las lógicas, formas y sentidos de la intervención. El estudio responde a una metodología de carácter exploratorio-descriptivo, con un enfoque cualitativo orientado a rescatar las tensiones presentes en los procesos de intervención social llevada a cabo por una ONG de características históricas.

Se revela la presencia de dos lógicas de intervención diferenciadas en la ejecución del programa de prevención focalizada en infancia, una asociada al control que responde a la institucionalidad y la otra a un registro emancipador, propias de la organización, lo que particulariza lo planteado por Carballeda $(2002,2010)$ sobre la presencia de una doble dimensionalidad en la intervención. Además, aparece la idea de la no intervención en la intervención institucional.
\end{abstract}

Palabras clave: Intervención social, $O N G$, tensiones, política social, infancia.

\begin{abstract}
In analyzing the social intervention processes developed by Non-Governmental Organizations (NGOs) linked to the implementation of the social policy of childhood, it emerge a serial of tensions, articulations and questionings through the logics, forms and sense of the intervention. The study responds to an exploratory-descriptive methodology, with a qualitative approach aimed at rescuing the tensions present in the processes of social intervention carried out by an NGO of historical characteristics. It reveals the presence of two logics of intervention differentiated in the implementation of the Program of Prevention Focalized in childhood, one associated with the control that responds to the institutionality and the other to an emancipatory registry, typical of the organization, which particularizes the one raised by Carballeda $(2002,2010)$ on the presence of a double dimensionality in the intervention. Also appears the idea of "no intervention" in institutional intervention.
\end{abstract}

Key words: Social intervention, NGOs, tensions, social policy, childhood.

\section{Antecedentes generales}

El surgimiento de las Organizaciones No Gubernamentales (ONG) en América Latina se encuentra vinculado a procesos ideológicos y al desarrollo de prácticas participativas concretas en diversos sectores sociales. Son estas organizaciones las que se posicionan en el espacio difuso entre lo público y lo privado. 
La importancia de las ONG a nivel mundial tiene sentido en su anclaje en la sociedad civil y en los profundos valores sociales que aparecen en los procesos de transformación social impulsados por éstas en las diversas épocas históricas, así como en su vinculación con el Estado y la sociedad.

Tal como lo señala Balbis, (2001 en Holguín, 2009, p. 25), "las ONG constituyen un fenómeno insoslayable en el escenario regional por su contribución al esfuerzo colectivo que las sociedades latinoamericanas y caribeñas llevan a cabo en procura de objetivos tan trascendentes como un desarrollo sostenible".

Las ONG en Chile se instalan con mayor desarrollo a partir de la década del 70, como respuesta a la dictadura y a su modelo de desarrollo político, económico y social (Grüninger, 2004). Su surgimiento transita desde un proceso espontáneo y como respuesta a necesidades específicas de la población hasta un proceso paulatino de institucionalización.

Este auge de las ONG posterior al golpe militar "no habría sido posible sin la existencia de factores externos favorables como son los períodos de menor represión, al apoyo financiero por parte de la cooperación internacional y la propia dinámica de los sectores sociales" de la época (Grüninger, 2004, p. 16).

Es posible identificar según lo plantea Spoerer (1995) cuatro tipos de ONG posterior a 1973 en Chile. Las primeras están relacionadas con el trabajo contra las violaciones a los derechos humanos; las segundas orientaron su trabajo a mitigar los efectos de la situación socioeconómica de los sectores populares. Luego, en 1977 aparece otro grupo de instituciones, asociadas al ámbito académico privado y como espacio de desarrollo intelectual. Y a partir de 1980, aparecen las ONG de Desarrollo, cuyo objetivo estaba orientado a la promoción y organización de sectores populares (Grüninger, 2004).

Con el proceso de transición a la democracia en la década de los 90, estas ONG se vinculan al Estado, canalizando todas las formas de cooperación solidaria internacional con Chile para el desarrollo e implementación de nuevos programas y acciones orientadas a legitimar al nuevo gobierno, a través de la transferencia profesional, técnica y política en materia social, que dieron sustento a las nuevas iniciativas implementadas por el Estado. Este vínculo de las ONG con la institucionalidad pública debilitó a las propias organizaciones y las subordinó, transformándose en entidades de prestación de servicios de las políticas implementadas y debiendo competir con otros actores la adjudicación de recursos para su funcionamiento.

\section{Intervención social y ONG}

Los nuevos escenarios sociales y la complejidad de los fenómenos abordados desde lo social han llevado a las ONG, así como a otros actores, a desarrollar procesos de intervención social que implican nuevas formas de aproximación a la sociedad.

Desde una mirada histórica, la intervención social surge marcada por una tradición normativa y con un propósito pedagógico, en tanto se espera que los sujetos de intervención aprehendan la modernidad y se integren a ella (Carballeda, 2002). La intervención realizada por estas organizaciones ha estado vinculada a un amplio espectro de necesidades, transformándose en un referente de abordaje de las diversas problemáticas sociales.

Las formas de intervenir las problemáticas sociales complejas se desarrollaron a través de procesos innovadores orientados a interponerse a las nuevas formas de padecimiento social, ya sea desde procesos de mediación, ayuda y cooperación, y al mismo tiempo como intromisión, injerencia e intrusión (Carballeda, 2002), generando en ocasiones procesos de intervención que tienden a la normalización, al control y al disciplinamiento social y en otros a la emancipación, a la liberación, a la autonomía y al reconocimiento de las condiciones históricas de los sujetos (Martínez, S., \& Agüero, J., 2015). La intervención social emerge impregnada de los postulados modernos tensionados en un contexto de contradicción, entre la promesa de emancipación y el sometimiento (Carballeda, 2010).

La intervención se comprende como un momento o espacio artificialmente producido, en tanto acción, donde sería dificultoso desprenderla de alguna de las dimensiones, dados sus aspectos fundacionales, que ya son contradictorios y presentan de modo tensional la emancipación-sometimiento. Según Carballeda, "... al ser la intervención un espacio, momento o lugar artificialmente constituido en tanto acción, desprenderla de una de las "caras de la moneda", separarla de esa cesión "hobessiana" de soberanía, implicará cierta dificultad, especialmente si tenemos en cuenta sus aspectos fundacionales" (2002, p. 93). Por tanto, implica la integración de la racionalidad en la vida cotidiana que es necesario zanjar previo a la resolución de los problemas sociales en sí mismos.

Una característica relevante de la intervención es que puede ser comprendida como dispositivo (Carballeda, 2002; 2010) que se entromete en un espacio en tanto se demanda su aparición desde los sujetos o más bien desde categorías de sujetos e instituciones. "(...) la intervención es un procedimiento que actúa y hace actuar, que produce expectativas 
y consecuencias. Así, la intervención implica una inscripción en ese "Otro" sobre el cual se interviene, quien a su vez genera una "marca" en la institución y desencadena una serie de dispositivos e instrumentos en ésta (Carballeda, 2002, p. 94)

En ese sentido, la idea de demanda se configura como el acto original, fundacional de la intervención, entendida ésta última como intervención particular, como intervención en los espacios microsociales; una aproximación a lo macrosocial desde lo microsocial. Intervenir involucra la configuración de una lógica del acontecimiento fundante de la demanda, desde cierta posición teórica (Carballeda, 2002).

Así, en cuanto a algunos planteamientos sobre las características de la intervención social en la actualidad, Carballeda aporta en primer término la noción de escenario: cambiante y particular, en tanto se puede modificar dentro de una misma trama. Por ello, la intervención en lo social "(...) se transforma en una herramienta de trabajo, en tanto pueda definir una secuencia de acciones, pero especialmente un horizonte" (2002, p. 57). Una intencionalidad de transformación-mantención, por ejemplo, donde existen sujetos que operan en estas tramas, pero que potencialmente podrían cambiarlas.

Desde esta premisa, los procesos de intervención desarrollados por las ONG se transforman en dispositivos de intervención que desde una lógica innovadora podrían integrar la visión del Otro, del sujeto de intervención, desarrollando nuevos acercamientos en que la palabra de éste, su cotidianidad e historicidad (Carballeda 2002; 2014) aporten a los espacios para el desarrollo de la intervención social. Esto en palabras de Rubilar implicaría poner en el centro de los procesos de intervención social a los "(...) propios excluidos, devolviéndoles su protagonismo restado, restaurando su presencia y fortaleciendo sus itinerarios de sentido" (2013, p. 59).

Lo que conlleva a desarrollar procesos de intervención desde la perspectiva de la alteridad, considerando al Otro como sujeto de posibilidades, comprendiendo la diferencia y el lugar que ocupa (Agüero \& Castro, 2008, en Castro \& Gutiérrez, 2017).

Sin embargo, el Estado como principal agente busca conducir las acciones de los sujetos respecto a enunciados tendientes a la normalización. Va pauteando discursos que regulan el tipo de familia ideal de nuestra sociedad, entre otras construcciones, configurando discursos sobre los sujetos y dejando marcas en las intervenciones sociales (Saavedra, 2015). Por tanto, el desarrollo de la política social y de la intervención está vinculado más a la reproduc- ción que a la transformación social (Morán Carrillo, 2006), lo que de algún modo comienza a tensionar el acercamiento a intervenciones emancipadores. En este contexto, las ONG se transforman en entes operadores de la política social, cuya intervención implica la búsqueda del ajuste de los sujetos a pautas, valores y normas sociales dominantes (Zúñiga, 2014).

Con esto, cobra relevancia el acercamiento a los distintos contextos o escenarios de intervención, observando tanto los procesos de subjetivación como los de producción particular en el contexto de intervención.

\section{Tensiones en el marco de la intervención social desarrollada por las ONG}

En consideración a cómo se va comprendiendo la intervención podemos indicar que se presentan una serie de tensiones, en distintas escalas en las que estas se desarrollan.

En este contexto, se presentarían tensiones significativas en la intervención social, en la relación Estado, política social e intervención no gubernamental. Para Sáenz (2010), existen tres tensiones en la intervención social. La primera sería el contexto de las actividades sin fines de lucro versus el escenario laboral remunerado, donde la ejecución de proyectos sociales se convierte en mercado competitivo. Una segunda tensión dada por la intervención social no gubernamental versus la crisis del Estado de Bienestar, donde se privatiza la intervención, pero se representa al Estado en la ejecución de la política pública y social. Y una tercera tensión referida a la política compensatoria versus el vehículo de transformación, espacio donde se reproduce y disputa la lógica del Estado y se intenta compensar las consecuencias negativas de los modelos adoptados por el mismo.

También podemos señalar tensiones en los discursos de los interventores, donde se presentan lógicas de promoción de la autonomía, buscando el fortalecimiento de los vínculos y las prácticas, guiadas por medio de la focalización y fragmentación de la población intervenida (Rueda \& Unás, 2007).

Otra tensión existente dice relación con la determinación de la intervención desde los espacios institucionales, lo que también sucedería en las ONG, sobre todo aquellas que actúan como ejecutoras de la política social. Para los interventores, es la institucionalidad la que les entregaría un rol, 
con relación al cual se definiría una determinada orientación de la intervención, generando en ellos un alto grado de frustración, en tanto los objetivos, metas, indicadores, etc., institucionales no reflejan los procesos de intervención que refieren desarrollar (González y Pérez, 2008), lo que se condice con lo planteado por Zúñiga (2014), al señalar que existen una serie de presiones desde la institucionalidad que amenazan las posiciones laborales de los interventores y limitan las posibilidades de innovación en la intervención.

Dentro de esa misma línea, Ponce (2011) en un análisis y sistematización de la relación entre instituciones y sectores populares en Argentina, a partir de una intervención realizada a fines de los años noventa, plantea que la política pública se materializa en instituciones, que tienden a entrar en tensión con las lógicas hegemónicas, configurándose espacios de intervención desde los que se levantan diagnósticos o lecturas de la realidad, que denominan ciertos comportamientos como negativos, categorizan a las personas que se supone tienen esos comportamientos y se prescribe una solución apropiada para estos sujetos, configurándose una tensión entre la política, la organización y la propia intervención.

Del mismo modo, (Rueda \& Unás 2007), en una investigación sobre las fisuras en los discursos de la intervención social contemporánea, plantean que se cuestiona la capacidad de la intervención para generar procesos de integración plena, pudiéndose asegurar qué prácticas de intervención podrían ratificar los procesos de exclusión. Esto implica que "el esquema de intervención es la reparación. Es decir, un conjunto de intervenciones técnicas sobre las poblaciones en riesgo con el fin de restaurar su funcionamiento normal, o en su defecto neutralizarlo" (Morán Carrillo 2006, pág. 223).

Esto cobra relevancia en las intervenciones desarrolladas por ONG colaboradoras del Servicio Nacional de Menores (SENAME), dedicadas a ejecutar programas de intervención en infancia en nuestro país, donde las acciones parecen responder a intencionalidades de control y de normalización hacia a los Niños, Niñas y Adolescentes (NNA), buscando mantener un determinado orden social que estos sujetos parecieran tensionar. En otros momentos, las acciones parecen facilitar una mayor búsqueda de emancipación o de actoría social para quienes son los sujetos de atención.

Existe un carácter contingente y conflictivo de la intervención social, lo que en la intervención con NNA tendría sus propias particularidades, dando cuenta de un espacio atravesado por una serie de tensiones socioculturales. Tensiones manifestadas en la coexistencia de una lógica de control social y una privatización de la intervención social, así como un énfasis en la protección y ampliación de los derechos de los NNA en el otro extremo. Estas tensiones se pueden plasmar en las distintas configuraciones que se realiza de los sujetos de intervención, en las

CUADRO N 1

\section{CATEGORÍAS DE ANÁLISIS}

\begin{tabular}{|c|c|c|}
\hline $\begin{array}{l}\text { Objeto de } \\
\text { Investigación }\end{array}$ & Categorías & Sub Categoría \\
\hline \multirow{11}{*}{$\begin{array}{l}\text { 1. Intervención } \\
\text { social }\end{array}$} & \multirow{4}{*}{$\begin{array}{l}\text { 1. Operacionalización } \\
\text { la intervención }\end{array}$} & 1.1.1.- Enfoques de Intervención \\
\hline & & $\begin{array}{l}\text { 1.1.2. Condicionantes de la operacionalización de la } \\
\text { Intervención }\end{array}$ \\
\hline & & 1.1.3. Metodologías y Estrategias de Intervención. \\
\hline & & 1.1.4. Acciones desarrolladas en la intervención. \\
\hline & \multirow{7}{*}{$\begin{array}{l}\text { 1.2. Horizonte de la } \\
\text { intervención }\end{array}$} & 1.2.1.- Concepciones sobre la intervención \\
\hline & & 1.2.2. Perspectivas de la intervención: de cambio y logro \\
\hline & & 1.2.3. Lo administrativo en la intervención. \\
\hline & & $\begin{array}{l}\text { 1.2.4. Configuración y relación con los sujetos de } \\
\text { intervención. }\end{array}$ \\
\hline & & 1.2.5. Problemáticas que originan la intervención \\
\hline & & 1.2.6. Roles en la intervención \\
\hline & & 1.2.7. Intervención histórica de la Organización \\
\hline
\end{tabular}

Elaboración Propia 
miradas adultocéntricas presentes, así como en los objetivos y lógicas de los propios programas de intervención (Vergara, 2009).

\section{Metodología y configuración del caso analizado}

El presente análisis se desarrolla desde una mirada dialéctica-interpretativa para producir conocimiento y acercarse a la realidad (Crabtree y Miller, 1992 en Valles, 1999).

El estudio es de tipo exploratorio-descriptivo con un enfoque metodológico de carácter cualitativo (Flick, 2007), ya que lo que se pretende rescatar son las tensiones presentes en los sentidos y prácticas de los actores que participan en la ejecución de un Programa de Prevención Focalizada (PPF). Se desarrolló un movimiento inductivo-deductivo que permitió conocer en profundidad el objeto de estudio.

Para orientar el análisis se consideraron dos grandes categorías (Cuadro N 1) en las que se intencionó indagar para profundizar en las tensiones de la intervención. Éstas son: La operacionalización de la intervención, entendida como la concreción de aspectos metodológicos, estratégicos y técnicos de la intervención; y el horizonte de la intervención en el registro de las intencionalidades y los sentidos atribuidos a ésta por parte de los distintos actores participantes. En una primera instancia se consideran por separado, pero se comprenden como articulados y en relación dialéctica (Gonzalez-Saibene, 2014).

Para el desarrollo de esta investigación se utilizaron las técnicas de revisión documental (Valles, M. 1999), observación participante (García, 1994), entrevistas semiestructuradas (Gil, 2006) y análisis de contenido (Piñuel, 2002; Andréau, 2002). Se entrevistó a 6 miembros del equipo de intervención y a 8 NNA y sus familias.

Para la observación se consideraron los distintos momentos de la intervención, en una primera instancia se realizó de modo abierto y sistemático al espacio cotidiano, donde surge por ejemplo la subcategoría "Intervención histórica de la organización" (Ver cuadro N 1) y luego se desarrolló una observación focalizada a acciones de intervención específica, tales como sesiones de ingreso, visitas domiciliarias, entrevistas psicosociales e intervenciones grupales, etc.

El caso analizado fue seleccionado en base a los siguientes criterios: Ser una entidad que ejecuta programas de la Política de Infancia, durante 5 años de forma ininterrumpida a la fecha del estudio, en territorios específicos de la comuna de Viña del Mar, V Región de Valparaíso, Chile, cuyo origen organizacional se remonte al contexto sociopolítico de dictadura militar en Chile y conforme equipos de trabajo de diversas disciplinas y formaciones.

El contexto del caso es la ejecución del Programa de Prevención Focalizada (PPF) que aborda vulneraciones de derecho de mediana complejidad en población infantojuvenil, relevando la restitución de derechos en NNA, a partir de un trabajo principalmente familiar, por medio del fortalecimiento de competencias parentales y factores protectores contextuales. Está inserto en la oferta programática del SENAME y corresponde a la línea de prevención focalizada, siendo de carácter ambulatorio.

En el marco de su formación histórica, la ONG de desarrollo consigna como su misión la generación de programas y proyectos en las áreas de desarrollo local, infancia, medio ambiente y tecnologías apropiadas e investigación en sectores urbanos populares de vulnerabilidad social y exclusión con el fin de contribuir a la participación ciudadana y a la promoción de los derechos humanos. A través de la intervención social y comunitaria, la educación popular y el desarrollo sustentable (Sánchez, 2014). Como la mayoría de las ONG en Chile, inició su labor sin recursos financieros, mientras que a mediados de la década de los ochenta, la totalidad de éstos era de origen extranjero. Desde los años 90, la organización realiza proyectos financiados por diversas entidades públicas y municipios (Sánchez, 2014)

El proyecto cuenta al momento del análisis con 115 plazas, correspondientes a niñas, niños y adolescentes de 0 años a 17 años, 11 meses y 29 días, y sus familias.

La organización ejecutora presenta un equipo profesional compuesto por 1 directora, 2 trabajadoras sociales, 3 psicólogos, 1 sociólogo, 4 educadores y 1 secretaria (Sánchez, 2014).

La ejecución de este programa se enmarca en el objetivo general de "Restituir derechos vulnerados asociados a mediana complejidad, que afectan a NNA en el contex to familiar, previniendo su cronificación" (SENAME, 2013, p. 8). Esto a través del fortalecimiento de recursos personales de NNA, competencias parentales, promoción e incorporación de cogarantes, facilitar instancias de diagnóstico y sensibilización respecto a enfoque de género y potenciar la participación de NNA y sus familias a través de la promoción de derechos.

En este nuevo vínculo ONG-Estado, a partir de los 90 , en la que se enmarca la intervención realizada 
por la organización, aparecen una serie de tensiones que se evidencian en diversos aspectos de la cotidianidad de este quehacer y que analizaremos en lo sucesivo.

\section{Principales hallazgos en el análisis de caso}

Dentro de los hallazgos encontrados en el proceso de análisis, emerge la idea de una doble intervención. Carballeda (2002) plantea que dentro de la intervención social coexisten al mismo tiempo las dimensiones de control y de emancipación; sin embargo, desde los discursos de interventores y análisis de la intervención aparece la configuración de que en los procesos desarrollados por la organización existirían dos intervenciones diferenciadas y no dimensiones coexistentes en una misma intervención. Por una parte, se reconoce una intervención institucional que es vinculada a la lógica y objetivos del programa de SENAME, y por otra se registra una intervención histórica (vinculada a la educación popular). La presencia de estas dos intervenciones se refleja a través de la adopción de distintos enfoques y estrategias de intervención, así como la práctica de roles diferenciados en el equipo para cumplir una y otra intervención. A continuación revisaremos los principales hallazgos desde distintitos tópicos emergentes asociados a las subcategorías analizadas.

\section{De la carencia al vínculo}

En la práctica discursiva aparece de manera relevante la presencia del enfoque sistémico, en tanto sería incorporado en la medida en que permite la comprensión de las familias en sus respectivos contextos:

“(...) creo que principalmente un enfoque ecosistémico que nos ayuda a comprender a estas familias en su entorno" (TS 1$)^{1}$.

Este enfoque orienta el accionar de los interventores desde una perspectiva individual-familiar. Buscando recuperar la funcionalidad del sujeto de intervención, desde lógicas de control y reparación, una intervención impuesta como saber totalizante, que clausura el devenir subjetivo y categoriza (Castro-Serrano \& Gutiérrez, 2017) a los NNA y sus familias como sujetos carenciados. Su foco está puesto en las vulneraciones de derecho de NNA, las que estarían situadas en el contexto familiar, coincidiendo con la línea y visión del programa de SENAME. Frente a ello, una mirada más marginal y que pone un contrapunto a esta situación por parte de los integrantes del equipo sería la explicación de que estas vulneraciones también responden a situaciones estructurales que las definen y condicionan.

De ese modo, visibilizar a los NNA en el contexto del enfoque de derechos y responsabilizar a los adultos sobre éstos, desde una primera lectura, representa una idea consistente en términos del proceso de intervención y los objetivos hacia los que ésta se dirige. Aun cuando no todos los miembros del equipo identifican explícitamente esta mirada, sí aparece en sus discursos las referencias a una intervención familiar y contextual de ese tipo, donde se comprende a la familia como sistema y se incorporan elementos de análisis referidos a la funcionalidad o disfuncionalidad.

Una segunda mirada que también está presente en la intervención se asocia principalmente al desarrollo de prácticas con base en la educación popular y que estarían orientadas al desarrollo de una intervención social más emancipadora que busca la transformación social y revertir las condiciones de opresión y sometimiento (Martínez, S., \& Agüero, J., 2015).

Para el desarrollo de estas acciones de promoción y construcción conjunta, los educadores, particularmente, relevan la educación popular como base de la intervención:

"Nosotros hace tiempo hemos ido desarrollando una metodología de integración comunitaria, que tiene que ver con una mirada social comunitaria del sector, dándole énfasis a la participación y desarrollo de la gente en donde aplicamos algunas características y metodología, que tiene que ver con la educación popular" (ED 2).

La educación popular implicaría compartir y producir saberes y experiencias entre los miembros del equipo y los sujetos de intervención, para generar nuevas construcciones de saberes, donde independiente de lo que se intencione desde el equipo interventor, habitualmente se inclinarían por esa dinámica de compartir y construir con el otro.

Si esta mirada sobre los sujetos de intervención se proyecta hacia la de un sujeto histórico, con autonomía y ejercicio pleno de derechos, y donde los adultos, como todo el resto de la sociedad, asumen una cultura de derechos, es posible distanciarse de una perspectiva más funcionalista e integracionista y aproximarse mayormente a visiones críticas respecto del mismo fenómeno.

Desde el discurso de los interventores, esta intervención estaría vinculada al sello de la propia ONG,

1. Donde TS corresponderá a Trabajador Social, PS a Psicólogo, ED a Educador y SI a Sujeto de Intervención. 
que se visibiliza en la mantención de un abordaje territorial y grupal-comunitario, asociado a la promoción, goce y exigibilidad de derechos. Sería en este espacio donde se desarrollarían los vínculos de confianza, como base y soporte de las relaciones entre los interventores y los sujetos de intervención. Ello se evidencia en lo señalado por los educadores: “(...) tratamos que sea una relación fluida, horizontal, en lo posible que genere un cambio, interactiva se puede decir que sea ida y vuelta. Tratamos que sea de confian$z a$, tratamos que sea agradable... que la gente participe y confie en los talleres (...)" (ED 2).

Asimismo, desde los sujetos de intervención se releva la centralidad del vínculo y la confianza en la intervención:

“(...) nos tranquiliza, nos da confianza más que nada. Yo confí ciegamente en los dos, las dos personas que me tocaron para este sector" (SI 3).

El afecto cobra sentido en la relación de intervención. En la voz de los sujetos, los lazos son:

"ah, de confianza, cariños, amistad, po. Porque igual llevamos harto tiempo igual" (SI 4).

La convergencia de las miradas (interventor-intervenido) dan centralidad a la confianza como base y soporte de sus relaciones.

\section{Gestión de la vulneración sin rostro}

Con relación al foco de intervención, se puede observar en los discursos y prácticas de los interventores la existencia de una tensión entre lo planteado desde la institucionalidad (SENAME) y la ONG Histórica, dado que el foco central de la intervención social desde la ejecución de la política social de infancia estaría en la resolución de vulneraciones de derecho, haciendo énfasis en la estandarización de los perfiles de los sujetos y de la intervención, así como en el control y monitoreo de esta última, relevando los indicadores de gestión, manteniendo la visión de "beneficiarios" de programas sociales, sin lograr avanzar en la comprensión de las necesidades de los NNA como un derecho social no cumplido. En este registro, el equipo plantea:

"(...) Creo que te condicionan mucho, que tení que tener una intervención con el niño y con la familia, está bien, pero también hay un montón de cosas que se hacen y no están consideradas como proceso de vinculación, como proceso de intervención, como parte activa del proceso. Sólo les importa que veas a los niños y sus madres ni siquiera cuestionan la calidad de ese ver" (AS 1).

Este condicionamiento de los procesos de intervención a los requerimientos de la institucionalidad limitaría la posibilidad de reconocimiento del otro, de lo otro y de sus diferencias, reduciendo la inter- vención social a un carácter asistencial y reparatorio (Morán Carrillo, 2016).

Esta mirada tiende a comprender a los sujetos desde una condición de carencia y déficit, lo que conlleva a la configuración de un tipo de sujeto desprovisto de recursos. Direccionando así la intervención desde aproximaciones negativas y estigmatizadoras, que escinden o reducen al sujeto a esa situación o característica, no visualizando otros aspectos de la vida del sujeto, principalmente referidos a su potencialidad y capacidades ya desarrolladas.

Desde las prácticas históricas de la ONG, existirían algunas aproximaciones a la promoción, goce y exigibilidad de derechos, considerado además como un enfoque transversal a su intervención y a sus prácticas.

Para los educadores, la intervención de la organización "(...) obedece a su construcción histórica, a su impronta, a sus principios, la intervención completa, yo creo que si bien hay que responder a ciertas estructuras (...) nunca hemos dejado de lado lo otro, cada vez con más dificultad siento yo. (...) ha tratado siempre de generar esa impronta de trabajo y mantenerla" (ED 1).

En la misma línea, uno de los psicólogos del equipo plantea "(...)que cada vez se va perdiendo este sello, pero es por las directrices que vienen dispuesta por ser PPF, pero tratamos de ir y seguir trabajando en la comunidad, en las sedes, y no hacer tanto trabajo tanto en los box sino que en el terreno" (PS 2).

Desde el discurso se releva el intento de mantener una intervención integral, articulada a partir de otros enfoques e intencionalidades, que, por cierto, no se va configurando exenta de tensiones respecto a la mirada del marco regulatorio de la política social.

\section{De lo individual a lo colectivo}

En esta lógica de la doble intervención, se relevan estrategias metodológicas diferenciadas, relacionadas unas a la intervención individual-familiar y otras orientadas a la intervención colectiva y territorial.

Dentro de la intervención individual-familiar, se releva como uno de los momentos centrales de la intervención, la elaboración del diagnóstico, señalando además que para su desarrollo se requieren una serie de instrumentos, técnicas y procedimientos, entre los que destacan la entrevista en profundidad. Esto se refleja en lo planteado por uno de los trabajadores sociales:

"Como técnicas tenemos entrevistas, tanto individuales como familiares (...) línea de talleres grupales (...) espacios de asambleas, en base a exposiciones, tanto 
con la familia y la comunidad, y también el tema de la observación en donde hay pautas, en el inicio en el proceso, y en realidad siempre se trata de observar... También hay encuesta, evaluación de proceso, evaluación de género también (...) cuestionarios. Además la visita domiciliaria (...)" (TS 2).

A propósito de la centralidad de las estrategias individuales-familiares y del énfasis de la vulneración puesto en la familia, el foco en las competencias parentales que realiza el equipo se va configurando de a poco en central en la intervención. Esto se evidencia en la utilización de evaluaciones de competencias parentales y de funcionalidad familiar con el instrumento escala de evaluación familiar de Carolina del Norte (North Carolina Family Assessment Scale, NCFAS).

Paralelamente, de parte de los interventores, también se releva la centralidad que tendrían los espacios colectivos y talleres en el desarrollo de la intervención, dando cuenta de esta tensión, pero a su vez de la diferenciación permanente entre los dos tipos de intervención.

Estas estrategias y acciones grupales, así como las comunitarias, serían centrales en la intervención de la organización. En un primer orden, se relevarían las instancias grupales y en un segundo orden las comunitarias. Esto se evidencia en lo planteado por los educadores:

"Nosotros hace tiempo hemos ido desarrollando una metodología de integración comunitaria, que tiene que ver con una mirada social comunitaria del sector, dándole énfasis a la participación y desarrollo de la gente en donde aplicamos algunas características y metodología, que tiene que ver con la educación popular" (ED 2).

La tensión entre las dos lógicas de intervención planteadas se evidencia en el desarrollo de acciones y estrategias diferenciadas, que van respondiendo a cada una de estas. En palabras del equipo interventor:

"Los talleres es el motor del Programa, por otro lado, están las atenciones individuales, tanto con el niño o con el adulto, lo cual va por el SENAME" (PS 2).

Esto es interesante en tanto los sujetos de intervención, si bien refieren algunas atenciones vinculadas a lo individual-familiar, se centran principalmente en actividades recreativas y otras de carácter socioeducativo más ligadas a espacios colectivos. Es decir, que aun vivenciando esos procesos de diagnóstico y atenciones individuales-familiares, de todos modos relevan de manera significativa los espacios colectivos.

\section{Dos equipos en acción}

En relación con esta lógica de doble intervención, es posible visibilizar una diferenciación, dado que mientras el equipo de psicólogos y trabajadores sociales tendrían a su cargo los casos, desarrollando la línea de intervención individual-familiar, el equipo de educadores, por su parte, apoyaría la intervención en un trabajo más directo con los niños, niñas y adolescentes, desde la línea principalmente grupalcomunitaria y desde el trabajo con cogarantes, que también es una demanda del SENAME, pero que no aparece mayormente en el discurso de los miembros del equipo. Esta diferenciación es planteada por la organización en términos de la ejecución del Programa PPF, donde de algún modo se contempla esta estructura, con roles y tareas diferenciadas, lo que se puede evidenciar en lo que plantea un miembro del equipo ejecutor:

“(...) en las del diagnóstico, el fuerte la hacen psicólogos y asistente social. Los educadores tienen su fuerte en los talleres y convocatorias de los talleres, en las coordinaciones escolares o comunitarias, en el fondo ese es el fuerte de los educadores. Por tanto, es un trabajo en equipo, si nosotros necesitamos información, ellos nos aportan" (PS1).

En este contexto, los educadores se visualizan como equipo de apoyo desde la intervención que realizan, hacia el equipo de psicólogos y de trabajadores sociales, evidenciándose aún más la tensión entre las dos intervenciones, ya que si bien la labor de los educadores se considera como central para mantener el sello de la organización, ellos se ven como equipo de apoyo a la intervención más ligada a los objetivos de la institucionalidad (SENAME).

\section{El otro en escena}

En cuanto al rol que los interventores atribuyen a los sujetos en la intervención, estaría tensionado por una parte en cuanto los ubican como actores centrales, que guiarían el curso de la intervención, cuando presentan adherencia a ésta, visualizándolos de modo participativo, con un papel protagónico en los distintos espacios de intervención. Y por otra parte existirían sujetos que no adhieren a la intervención, no reconocerían las problemáticas de ingreso y no se lograrían responsabilizar por el proceso.

En relación con esto, los interventores señalan:

"Ellos son parte de todo de lo que nosotros hacemos, ellos son quienes nos guian a ver formas distintas (...) Pero yo siento que la forma que toma la intervención, en el fondo lo llevan ellos, ellos llevan la intervención. Como te digo, nosotros somos el 20\% y ellos son el $80 \%$ 
de la intervención, las familias, cuando ellos quieren, cuando hay adherencia, cuando se quiere un cambio también" (PS 1).

La visión más negativa sobre los sujetos de intervención se vincula luego con que el equipo pretende trabajar en aumentar los grados de conciencia de éstos, a propósito de las situaciones que de algún modo han originado la intervención.

Respecto al rol que los mismos sujetos de intervención identifican de sí mismos en la ejecución del Programa, destaca el que tienden a asociarlo directamente a las actividades en las que participan y a la relación de ayuda que identifican en la intervención, relación donde prima la recepción de ayuda más que la construcción conjunta, lo que se evidencia en lo que refieren los sujetos de intervención:

"Yo creo que es muy bueno, ayudan a muchos niños, empezando yo ahora también por los libros que a los niños le piden en el colegio y uno no tiene como plata pa comprarlos y estando el niño ahí unos los pide y tiene la ayuda para los libros, que es un gasto menos (...) Y lo otro es que sacan a los niños que están parados en la esquina y cosas y es buena la ayuda" (SI 1).

Los sujetos de intervención señalan que esta relación de ayuda implica un Otro que tendría cierto saber y algo que entregar, que por cierto podría ser conducción o control. En palabras de estos sujetos de intervención:

“(...) ellos nos enseñan, nos van explicando cómo se hacen las actividades, ellos también trabajan con nosotros, traen sus materiales, yo los he visto trabajar en las actividades siempre (...)" (SI1).

Ante esta conducción o control, los sujetos de intervención podrían responder de diferentes maneras como adherencia, resistencia, etc. Desde allí, se tiende a no visibilizar, al menos por parte de los sujetos entrevistados, su participación en la definición o diseño de alguna actividad, lo que tensiona de algún modo la idea de potenciar espacios de participación desde la misma intervención.

Esto también es reforzado cuando los sujetos de intervención visualizan la figura de los interventores, donde básicamente aparece una mirada de éstos como aquéllos que enseñan o entregan algún tipo de conocimiento, por tanto en contraparte se va configurando un receptor de ayuda. Esta idea del interventor que entrega conocimiento o enseña, resulta transversal a la intervención, en tanto la mirada del interventor que participa a la par con el sujeto de intervención está principalmente asociada a los espacios colectivos.

\section{Más de un prisma para los problemas}

Otro elemento que tensiona los procesos de intervención desarrollados por la organización se relaciona con la mirada acerca de las problemáticas de intervención.

El equipo interventor hace referencia principalmente a la vulneración de derechos asociada a los contextos familiares, identificando una serie de situaciones que incluso están tipificadas en el Programa como causales de ingreso y que responderían al perfil de sujetos con vulneraciones de derecho de mediana complejidad, que los lineamientos del PPF también definen. El equipo señala que esto estaría relacionado con:

"(...) los estilos familiares que tenemos, de todas las problemáticas familiares del sector, además no hay escuela para ser papá o mamá, y por eso a veces hay actitudes crónicas que pueden llevan al mal funcionamiento familiar, a la negligencia bastante severa que hacen que un equipo social se haga cargo y que se le posibilite ayuda a esta familia. Hay casos en los cuales conocemos muchos niños que pasan casi todo lo día solos, cosa que realmente todavía pasa. En el sector se ve el tema de las amistades inadecuadas, de repente el uso y abuso de consumo de alcohol y drogas, pérdida en el interés por el estudio, vagancia, embarazo precoz, enorme variedad de casos (...)" (ED 2).

De todos modos, se debe destacar que también aparece paralelamente, en el equipo, una mirada que explica estas vulneraciones de derecho, asociadas a las situadas en el contexto familiar, pero que estarían vinculadas a contextos mayores, siendo una aproximación un tanto más estructural.

En cuanto a la mirada de los sujetos de intervención respecto a las problemáticas que originan su ingreso, se presentan una variedad de explicaciones, que oscilan entre situaciones que ellos no conciben como problemas y que terceros habrían denunciado como tales, el desconocimiento de las problemáticas o motivos del ingreso y la búsqueda de ayuda o participación voluntaria. Ello se evidencia en las siguientes citas:

"(...) la injusticia, por eso (...) por malos entendidos que yo nunca estuve en el lugar cuando sucedió los malos entendidos (...) pero igual" (SI 2).

Esto es coincidente con lo planteado por los miembros del equipo, quienes refieren desconocimiento, no problematización y escasa responsabilización de parte de los sujetos de intervención. Pero al mismo tiempo: "A mí me derivaron por mi nieta menor, porque cuando yo la traje ella era muy agresiva, cuando yo me hice cargo de ella (...) con la tía del jardín, le pegaba 
patás, combos, le pegaba a los compañeros, pateaba las puertas y por eso me mandaron a... y de ahí yo pedi ayuda para mis dos nietas mayores también (...)” (SI 2.).

\section{Apuestas de adaptación-transformación}

La organización debe responder a los lineamientos de las orientaciones técnicas que le entrega el SENAME, en ellas se estipulan objetivos específicos que no pueden ser modificados y que deben orientar las acciones en la intervención al fortalecimiento de los recursos personales de NNA, al fortalecimiento de las competencias parentales y a la promoción de la incorporación de cogarantes en el proceso de intervención (SENAME, 2013). Al analizar los objetivos específicos del programa con el que trabaja la organización, encontramos que nuevamente aparece una dualidad de intervención. Se puede indicar que efectivamente están en sintonía con lo que SENAME solicita en sus bases técnicas. Los dos primeros objetivos apuntan al desarrollo de habilidades y competencias con relación al trabajo con NNA y sus familias, centrándose en una mirada más bien funcionalista, donde se pretende normalizar, por una parte, a los NNA y por otra, a sus familias, respondiendo a la idea de que los NNA de ciertos territorios focalizados como "vulnerables" son vulnerados y están debilitados o disminuidos en sus habilidades, en tanto sus familias tienen disminuidas o directamente no poseen las competencias parentales que favorecerían el cuidado y desarrollo integral de éstos.

Así, al considerar modelos culturales dominantes en términos de la familia y sus funciones, estos sujetos deben integrarse al orden normativo, pero pudiendo reintegrarse sólo al lugar social que les corresponde, una vez que estén habilitados, según las normas que de modo explícito e implícito encarna el SENAME, a través del Programa. Con ello se busca que el sujeto no altere el equilibrio social, incorporándose a éste y adscribiendo al modelo y orden de sociedad existente.

En este sentido, esa integración o adaptación al sistema puede ser obstaculizada por la propia disfunción o incompetencia presentada por los individuos, surgiendo desde allí la necesidad o justificación de una intervención diseñada desde la institucionalidad. En palabras de Ponce de León y Paiva "... disfunción entendida como las consecuencias que obstaculizan la adaptación o ajuste al sistema..." (Ponce de León y Paiva, 1995 p. 93).

Esto se relaciona con lo que plantea Corvalán (1997) respecto al paradigma integracionista, en tanto la disfunción o desviación al orden social son elementos poco deseables para éste, por tanto deben corregirse, siendo el Estado el agente principal en conseguir esta corrección y la consiguiente integración de los individuos desviados. Por tanto, este sería el modo de preservar el equilibrio social en el sistema (Morán Carrillo, 2006)

Por otra parte y a propósito de una mirada distintiva se podrían indicar los objetivos que la organización incluye en la ejecución del Programa, como creación propia, estando referidas a una visión más crítica que coexiste con la indicada anteriormente. De esa manera, estas declaraciones expuestas en los objetivos por parte de la ONG se podrían asociar a perspectivas que tienen como meta la transformación social, presentando un horizonte emancipador. En ese marco, se levantan y destacan los objetivos, referidos a facilitar instancias de diagnóstico y sensibilización sobre el enfoque de género con los distintos actores involucrados en la intervención y potenciar la participación de los sujetos de intervención a través de instancias de promoción de derechos, respectivamente (que por cierto supera a la mirada de sólo centrarse en la vulneración).

Esto, de algún modo, se intenciona en espacios colectivos de trabajo (trabajo grupal, talleres, asambleas, encuentros familiares, acciones comunitarias) que desarrolla el proyecto. Sin embargo, en términos de claridad de estos objetivos y de algunas acciones asociadas a ellos, según lo observado, no se cuenta con una operacionalización sistemática, articulada, transversal y constante de acciones que permitan desarrollar estos procesos, ni con indicadores construidos de modo que se pueda dar cuenta de estas intencionalidades, procesos y, por supuesto, también sus resultados.

Nuevamente aquí aparece una tensión, en tanto se plantean y operacionalizan objetivos asociados al funcionalismo y al paradigma integracionista, a su vez que se presentan objetivos más cercanos a miradas críticas; miradas que propenden al control y a la normalización y otras más cercanas a la emancipación, y que en este caso están presentes en la ejecución de un mismo programa.

\section{La no intervención en la otra intervención}

En esta lógica de la doble intervención desarrollada por el programa, aparece la idea de la No Intervención en la Otra Intervención. La Otra Intervención sería para los interventores todas aquellas acciones llevadas a cabo para la ejecución del PPF. Dentro de esta intervención reconocen la existencia de una No Intervención, donde el eje central está dado por las acciones administrativas que implicaría la ejecución 
de la política social; los miembros del equipo de intervención señalan que es en esta No Intervención donde se presentarían limitantes para la intervención, así como dificultades para incorporar acciones no reconocidas por la institucionalidad. En sus discursos señalan:

"Yo creo que los tiempos condicionan mucho la intervención, yo creo que (...) las exigencias administrativas que son muy altas; por ejemplo, yo no me quejo de la elaboración del diagnóstico porque es un insumo para mi trabajo, pero sí me quejo de que tengo que enviar cada informe al tribunal, de que a SENAME se le ocurre cada cuestión, que tengo que estar subiendo a una plataforma que es súper completa, por lo tanto ya no me demoro 2 minutos en hacerlo, sino que estás 5 minutos para subir la intervención y estás a fin de mes y colapsa el sistema, de esas cosas me quejo (...)" (TS 1)".

Desde el discurso planteado por el equipo, la idea de esa otra intervención está asociada a la casuística, acorde a los objetivos y lógica del Programa PPF, siendo la intervención propia de la institucionalidad y no de la organización. Sería una intervención que además tendría una sobrecarga de tareas y gestiones administrativas asociadas, que en sí mismas los miembros del equipo consideran que no constituirían intervenciones y que les restaría tiempo para las intervenciones directas. Según el equipo interventor, existiría una dificultad para articular las exigencias administrativas del Programa con la forma particular de la intervención que tendría el equipo, donde las demandas y productos administrativos le restarían tiempo a las intervenciones directas con las familias, aunque de todos modos se seguiría respondiendo a los requerimientos de lo administrativo. Esto se refleja en lo planteado por los educadores:

"Entonces el articular nuestra forma de ver... de intervención en el proceso de trabajo (...) con las exigencias del Programa digamos (...) es difícil, y te resta tiempo, $y$ ahi también se genera otro factor que influye en la intervención, que es el tema frustración, que te terminas frustrando, porque decí 3 días de la semana completo haciendo este informe para dedicar un trabajo con la familia de dos horas a la semana. Y tu decí algo está mal aquí, po. Siendo que esto debería ser al revés, cachay. Pero respondí a esa dinámica de trabajo (...)" (ED 1).

Así, el diseño de diagnósticos, planes, informes al Tribunal, registros en plataformas solicitadas y otras gestiones consideradas como administrativas (comparecencia en Tribunales, coordinación con otras instituciones), se podrían contemplar en esta no intervención. Eso al menos es lo que se puede interpretar del discurso de los miembros del equipo, ya que contraponen estas acciones a la intervención directa con los sujetos, con las familias, con los territorios. Ello contrasta de manera significativa con la centralidad que tienen estas acciones, en términos de volumen de demanda permanente y a propósito de que constantemente se busca cumplir con las mismas.

En este mismo ámbito, los miembros del equipo identifican la presencia de dificultades administrativas para incorporar acciones no reconocidas por la institucionalidad. Estos refieren un condicionamiento de parte de la institucionalidad, donde más allá de cuestionar el número de intervenciones directas demandadas, se resiente la idea de que habría una serie de acciones que despliegan y que no serían reconocidas como parte de la intervención. Así, la institucionalidad se centraría en que se realicen los requerimientos en tipo, en número, en un registro de control, más que cuestionando la calidad de éstos o interesándose por los procesos de intervención. Esto se refleja en lo planteado por uno de los educadores:

"(...) deja de lado o deja afuera un montón de cuestiones que para nosotros son importantes y no están consideradas ahí, son importantes como institución, entonces y que no la queremos perder, porque tiene que ver con (...) con lo de verdad que creemos que genera cambios, entonces hay que incorporarlas y esa incorporación es difícil porque te has cuestionado siempre ipor qué estás haciendo esto? ¿por qué gastaste plata en esto? y eso genera una tensión" (ED 1).

Así, existirían acciones que no serían consideradas en la intervención, en los registros de intervención y que tendrían que ver con los objetivos de fondo de la organización, asociados a su práctica histórica. Allí, se presentan dificultades para su incorporación, dado los cuestionamientos a esas acciones por parte de la institucionalidad o a los costos económicos que éstas mismas implican.

\section{Conclusiones}

En esta lógica de vínculo Estado-ONG, es posible evidenciar una serie de tensiones que se manifiestan en las formas en que se desarrollan los procesos de intervención de las organizaciones que operan la política social de infancia en la actualidad y que intentan mantener ciertas prácticas históricas con las que surgieron.

En este contexto aparecen tensiones relativas a la coexistencia de una lógica de control social y una privatización de la intervención social, así como un énfasis en la protección y ampliación de los derechos de los NNA en el otro extremo (Vergara, 
2009). Esto nos remite al carácter contradictorio de la intervención (Carballeda 2002) y nos hace mirar lo que refiere Vergara (2009), sobre lo conflictiva y contingente de la intervención social y cómo ésta es atravesada por tensiones socioculturales. Éstas, en el caso de la intervención en infancia, no sólo se vinculan, por ejemplo, a la configuración de un menor o sujeto vulnerable o a la consideración de éste como un sujeto histórico o cómo se juegan en la intervención las visiones adultocéntricas que pueden estar enraizadas entre los propios interventores que levantan el discurso del enfoque de derechos, sino que esto también es plasmado en las intencionalidades de los programas, en los objetivos, como así también en las acciones desarrolladas, conformando acciones que circulan entre los mandatos de la institucionalidad pública y las apuestas de intervención de la propia organización, donde se aprecian prácticas vinculadas al control y normalización de los niños, niñas, jóvenes y sus familias y, al mismo tiempo, acciones que parecerían facilitar una mayor búsqueda de emancipación y de actoría social. Esto implica que las intervenciones sean operacionalizadas en el desarrollo de esta idea de una doble dimensionalidad (Carballeda 2002, 2010), pero que, para los interventores, se configuraría como dos intervenciones diferenciadas (Cuadro N 2).

Esta doble intervención es operacionalizada de manera diferenciada a través de enfoques, metodologías, estrategias, acciones y equipos para la ejecución del programa PPF, como se puede observar en el cuadro anterior.

Esta configuración, por parte de los interventores, se podría explicar dada la necesidad de las ONG de mantener, al menos discursivamente y con algunas aproximaciones operativas una práctica histórica, lo que les permitiría conservar cierta identidad y no subsumirse completamente a reconocer una mera operación de la política social. Mantener esta práctica histórica se transforma en un proceso complejo, dada la preeminencia de la lógica institucional que se traduce en tensiones respecto a la sobrevivencia como organización (licitación, competencia), la centralidad y condicionamientos que mantiene en la intervención, así como la limitación para mantener apuestas propias, configurándose más bien estas intervenciones diferenciadas en vinculaciones de una misma intervención, de la ejecución de un programa en específico, de un cierto dispositivo que allí se articula de modo particular y deja marcas especificas en los participantes.

El responder a dos lógicas por una parte cumple con los objetivos reconocidos como propios de la institucionalidad, genera en el equipo una sobrecarga en términos administrativos, restándoles tiempo para las intervenciones directas. Al mismo tiempo, limita el mantener aspectos propios y distintivos de la intervención histórica de la organización, puesto que presentaría dificultades para validarla, transversalizarla, evidenciarla y además articularla con la otra intervención institucional.

Esta tensión existente en la presencia de una doble intervención, en tanto la operacionalización de la lógica institucional de la política de infancia y el intento por mantener prácticas históricas desde las ONG, en la articulación de un dispositivo particular de intervención, no se traduce en un sujeto pleno en el ejercicio de sus derechos, ni tampoco en un

CUADRO N 2

INTERVENCIONES PRESENTES EN EL CASO

ANALIZADO

\begin{tabular}{|l|l|l|l|l|}
\hline \multicolumn{1}{|c|}{$\begin{array}{c}\text { Tipo de } \\
\text { Intervención }\end{array}$} & \multicolumn{1}{|c|}{$\begin{array}{c}\text { Perspectiva y } \\
\text { Enfoque }\end{array}$} & $\begin{array}{c}\text { Foco de la } \\
\text { Intervención }\end{array}$ & $\begin{array}{c}\text { Metodología y } \\
\text { Estrategia de } \\
\text { intervención }\end{array}$ & $\begin{array}{c}\text { Principal res- } \\
\text { ponsable de la } \\
\text { Intervención }\end{array}$ \\
\hline $\begin{array}{l}\text { Intervención } \\
\text { Institucional } \\
\text { (Programa PPF) }\end{array}$ & $\begin{array}{l}\text { Funcionalista- } \\
\text { Sistémico e } \\
\text { Integracionista }\end{array}$ & $\begin{array}{l}\text { Vulneración de } \\
\text { derechos }\end{array}$ & $\begin{array}{l}\text { Intervención Directa } \\
\text { individual-familiar }\end{array}$ & $\begin{array}{l}\text { Equipo Profesional } \\
\text { (Psicólogos/as y } \\
\text { Trabajadores/as } \\
\text { sociales }\end{array}$ \\
\hline $\begin{array}{l}\text { Intervención } \\
\text { Histórica (ONG) }\end{array}$ & $\begin{array}{l}\text { Aproximación a } \\
\text { miradas críticas, } \\
\text { emancipatorias. } \\
\text { Educación Popular. } \\
\text { Centralidad en el } \\
\text { vínculo. }\end{array}$ & $\begin{array}{l}\text { Aproximaciones } \\
\text { específicas a } \\
\text { promoción, cultura } \\
\text { y ejercicio de } \\
\text { derechos. }\end{array}$ & $\begin{array}{l}\text { Intervención } \\
\text { Colectiva: Talleres } \\
\text { e intervención } \\
\text { territorial y } \\
\text { comunitaria }\end{array}$ & Educadores/as \\
\hline
\end{tabular}

Elaboración propia 
actor social que participe activamente de los procesos de transformación social, sino que más bien se configura en un mero receptor de ayuda.

La lógica institucional que se va plasmando entonces en la política social gana espacios en contextos territoriales donde las ONG desarrollan su quehacer. Resta espacios a posibles prácticas históricas que se requiere mantener incluso a posibles improntas que estas $u$ otros tipos de ONG quisieran desplegar desde las lógicas y objetivos propios, pero al ser operadoras de la política social quedan limitadas, configurándose como reproductores de la visión de normalización de la política social y quedando tensionados y limitados los espacios para apuestas interventivas alternativas o incluso más críticas, primando intervenciones orientadas a preservar el equilibrio social desde una lógica de control y normalización social (Morán Carrillo, 2006). Esta mirada tecnocrática y tradicional del otro, que sobrevalora los indicadores y la gestión tiende a invisibilizar al sujeto (Castro \& Gutiérrez, 2017), perdiendo de vista la subjetividad de los actores en la intervención social.

En ese sentido, cobra relevancia reforzar la idea de que la producción de conocimiento es clave no solo para potencialmente mejorar la intervención, sino que también para validar intervenciones que tensionen la política social y que podrían desarrollarse desde posicionamientos más críticos. Así, la invitación es seguir aportando a la disciplina (o disciplinas) investigaciones en el contexto de la intervención, desde y también para la intervención social.

Otra pista para hacer frente a estas limitaciones de la política social es la pertinencia de articular propuestas desde miradas críticas que replanteen la construcción del vínculo y el lazo social, la mirada hacia el otro y el protagonismo del sujeto en los procesos de intervención social, lo que se traduce en avanzar hacia un horizonte de intervención que reconstruya solidaridades y que permita fortalecer los lazos sociales, revinculando al sujeto con los otros, con su cultura, su historia en el marco de nuevas forma de asociación, desarrollando nuevos acercamientos en que la palabra del sujeto, su cotidianidad e historicidad sean relevados en el desarrollo de la intervención social. Esto se traduce en el reconocimiento de lo histórico, lo colectivo y lo territorial (Carballeda, 2002; 2008; 2014).

Este fortalecimiento de los lazos sociales implica construir un vínculo con el otro que permita develarlo y entenderlo, reconociendo al otro como sujeto de posibilidades, como sujeto diverso. Im- plica entender que el acontecimiento de encuentro, de diálogo (Rubilar, 2013) con ese otro nos lleva a entrar en comunión con él, reconociéndolo como legítimo otro en la intervención. Es decir, el argumento para fundar la intervención se sitúa desde el otro, de la diferencia y el lugar que ocupa el otro (Castro \& Gutiérrez, 2017; Agüero \& Castro, 2008). Esto implica el desarrollo de procesos que propicien en definitiva la emancipación del sujeto de intervención, el reconocimiento del sujeto libre y autónomo. Procesos de profundización democrática y constitución del sujeto político pueden ir tensionando y ganando espacios que contrarresten las lógicas institucionales que estandarizan al sujeto, que lo anulan y no lo dejan ver, aparecer, que limitan el encuentro cara a cara en la intervención (al mediarlo con indicadores; estandarizados, modelos de ajuste, normalizaciones, etc.). Esto se traduce en una vuelta al otro, pero no solo humano y que me permite ser, sino que también al sujeto liberado, autónomo, histórico y con condiciones materiales y simbólicas particulares, pero también con el potencial de transformar o al menos tensionar los escenarios en los que se desenvuelve.

Estas aproximaciones no son reproducciones mecánicas de enfoques o perspectivas anteriores, sino que re-lecturas a la luz de los contextos o escenarios sociales actuales, de sus tensiones y complejidades, que deben ser articuladas con proyectos y horizontes de intervención social vinculados a configuraciones ético-políticas más o menos claras y de carácter crítico. Por ello la invitación es a seguir leyendo y desarrollando intervenciones desde registros complejos donde se consideren las distintas articulaciones, escenarios, actores y producciones particulares de redes que direccionan la intervención y van configurando cierto tipo de subjetivaciones.

\section{Referencias bibliográficas}

AGÜERO, J. \& CASTRO, B. (2008). La clausura categorial del concepto: marginalidad nómada (Aproximaciones teóricas para una nueva comprensión de la marginalidad), en Revista de la Academia, núm. 13, septiembre-diciembre, Chile: Universidad de Humanismo Cristiano, p. 11-23.

ANDRÉU, J. (2002). Las Técnicas de Análisis de Contenido: Una Revisión Actualizada. Documentos de trabajo: Serie Sociología. Fundación Centro de Estudios Andaluces.

CARBALLEDA, A. (2014). La intervención social en los escenarios actuales: una mirada al contexto y el lazo social, en Intervención, núm. 3, Chile, U.A.H., p. 57-60. 
CARBAllEDA, A. VI Época, Número 1 (diciembre 2010). La intervención en lo social como dispositivo. Una mirada desde los escenarios actuales. TRABAJO SOCIAL UNAM, Ciudad de México (p. 46-59).

CARBALlEDA A. (2002). La intervención en lo social. Exclusión e integración en los nuevos escenarios sociales ( $1^{\mathrm{a}}$ Edición). Editorial Paidós. Buenos Aires, Argentina.

CASTRO, B. \& GUTIÉRREZ, C. (2017). Intervención Social y Alteridad: Una aproximación Filosófica desde Lévinas, en Andamios, Volumen 14, núm 33, eneroabril, p. 217-239.

CORVALÁN, J. (1997). Los paradigmas de lo social y las concepciones de intervención en la sociedad. En: Estudios sociales, No. 92, trimestre 2 .

FLICK, U. (2007). Introducción a la investigación cualitativa. Editorial Morata. Madrid, España.

GARCIA FERRANDO, M, Y OTROS (1994). "El Análisis de la Realidad Social: Métodos y Técnicas de Investigación”. Alianza Editorial, Madrid, España.

GIL FLORES, J. (2002). Seminario sobre las técnicas de entrevista de entrevista y observación. Universidad de Sevilla, Granada, septiembre 2002.

GONZALEZ-SAIBENE, A. (2014). Acerca de la intervención, en RUMBOS TS, año X, No 11 . Chile. Universidad Central, p. 22-40.

GONZÁLEZ, A. \& PÉREZ, L. № 79 (julio 2009). Palabras y cosas para el Trabajo Social: Sentidos y significados presentes en las estrategias de intervención utilizadas por los y las trabajadores sociales en la Región Metropolitana. Revista de Trabajo Social PUC. p. 65-77.

GRUNINGER, S. (septiembre de 2003). Las ONG durante la Transición Chilena: Un análisis de su respuesta ideológica frente a su incorporación en políticas sociales de índole neoliberal. Revista Mad. No. 9. Departamento de Antropología. Universidad de Chile. Recuperado el 13 de septiembre de 2016. http://rehue. csociales.uchile.cl/publicaciones/mad/09/paper06.pdf.

HOLGUín, C. J. (2009). El tercer Sector en el Proceso de Implementación de la Política Pública frente al Desplazamiento Forzado y su Relación con la Construcción de Capital Social. En: Revista Prospectiva. Universidad del Valle. N. 14.

MARTÍNEZ, S. \& AGÜERO, J. (2015). La intervención social desde la perspectiva del trabajo social emancipador. En Intervención, núm 4, Chile, U.A.H., p. 9-16.

MORÁN-CARRILLO, J. M. (2006). Fundamentos del trabajo social: trabajo social y epistemología. Editorial Tirant lo Blanch. España.

PIÑUEL, J. (2002) Epistemología, metodología y técnicas del análisis de contenido. Universidad Complutense de Madrid, Estudios de Sociolingüística 3(1), p. 1-42.
PONCE, G. (2011). Hacia una redefinición de la relación entre las instituciones y los sectores populares. Capítulo en libro: Trabajo Social de Hoy. Experiencias de campo e intervenciones profesionales. Editorial Espacio (p. 67-125).

PONCE DE LEÓN \& PAIVA, D. (1995). Matriz funcionalista. En: Perspectivas metodológicas en trabajo social. Diversos autores; p. 90-111. ALAETS-CELAETS.

RUBILAR, G. (2013). Imágenes de Alteridad. Reflexiones y aportes para el trabajo social en contextos de pobreza y exclusión, Santiago: Ediciones Universidad Católica de Chile.

RUEDA, A. \& UNAS, V. (2007). Fisuras en los discursos de la intervención social. Contemporánea. En revista CS. Universidad ICESI, Colombia. Revista CS. $N^{\circ} 1$ Seguridad e intervención social, p. 217-317).

SAAVEDRA, J. 2015. Cuatro argumentos sobre el concepto de intervención social Cinta moebio, p. 135-146. Disponible en www.moebio.uchile.cl/53/saavedra.html.

SÁEZ, J. (mayo 2007). Temas de reflexión en la intervención social. Universidad ICESI, Colombia. Revista CS. N 1 Seguridad e intervención social., p. 189-215.

SÁNCHEZ, M. (2014). Estudio de caso: "Tensiones en los sentidos y prácticas de intervención de los actores que participan de la ejecución de programas territoriales de infancia: el caso del P.P.F., Viña del Mar". Tesis para optar al grado de Magíster Interdisciplinario en Intervención Social. U.A.H., Santiago, Chile. No publicada.

SENAME. Departamento de Protección de Derechos Área de Gestión Programática Línea de Prevención (febrero 2013) Bases Técnicas Para Concurso de Proyectos Programa de Prevención Focalizada.

VALLES, M. (1999). Técnicas cualitativas de investigación social. Reflexión metodológica y práctica profesional. Síntesis Sociología. España.

VERGARA, A. (2009). La intervención social como conflicto. El caso de la infancia y juventud en Chile. El observador $\mathrm{N}^{\circ}$ 3. Enero 2009. Publicación trimestral Servicio Nacional de Menores.

ZÚÑIGA, R. (2014). La intervención - y las intervenciones, en Intervención, núm 3, Chile, U.A.H., p. 10-18. 